Electrical imaging for localizing historical tunnels at an urban environment

This content has been downloaded from IOPscience. Please scroll down to see the full text. 2015 J. Geophys. Eng. 12674

(http://iopscience.iop.org/1742-2140/12/4/674)

View the table of contents for this issue, or go to the journal homepage for more

Download details:

IP Address: 157.92.4.75

This content was downloaded on 30/06/2015 at 13:29

Please note that terms and conditions apply. 


\title{
Electrical imaging for localizing historical tunnels at an urban environment
}

\author{
Ana Osella ${ }^{1}$, Patricia Martinelli ${ }^{1}$, Vivian Grunhut ${ }^{2}$, Matías de la Vega ${ }^{1}$, \\ Néstor Bonomo ${ }^{1}$ and Marcelo Weissel ${ }^{3}$ \\ ${ }^{1}$ Departamento de Física, Facultad de Ciencias Exactas y Naturales, Universidad de Buenos Aires- \\ IFIBA, CONICET, Ciudad Universitaria, Pabellón 1, 1428 Buenos Aires, Argentina \\ ${ }^{2}$ Departamento de Matemática y Ciencias, Universidad de San Andrés-CONICET, Buenos Aires, Argentina \\ 3 Unidad de Gestión Plan Integral de Intervenciones Manzana de las Luces 2010-2016, Comisión \\ Nacional de Museos, de Monumentos y Lugares Históricos, Depto. de Humanidades y Artes, Universidad \\ Nacional de Lanús, Buenos Aires, Argentina \\ E-mail: osella@df.uba.ar
}

Received 4 August 2014, revised 29 May 2015

Accepted for publication 8 June 2015

Published 26 June 2015

\begin{abstract}
We performed a geophysical study at a historical site in Buenos Aires, Argentina, corresponding to the location of a Jesuit Mission established during the $17^{\text {th }}$ century, remaining there until the 18 th century. The site consisted of a church, cloisters, a school, orchards and a procurator's office; also several tunnels were built, connecting the mission with different public buildings in the town. In the 19th century the Faculty of Sciences of the University of Buenos Aires was built in a sector of the site originally occupied by an orchard, functioning until its demolition in 1973. At present, this area is a cobbled square. With the aim of preserving and restoring the buried structures, work was carried out in this square looking for tunnels and remains of the basement of the old building.

Considering the conductive features of the subsoil, mainly formed by clays and silt, the complex characteristics of the buried structures, and the urban localization of the study area with its consequent high level of environmental electromagnetic noise, we performed prefeasibility studies to determine the usefulness of different geophysical methods. The best results were achieved from the geoelectrical method. Dipole-dipole profiles with electrode spacings of 1.5 and $3 \mathrm{~m}$ provided enough lateral and vertical resolution and the required penetration depth. Reliable data were obtained as long as the electrodes were buried at least $15 \mathrm{~cm}$ among the cobble stones. Nine 2D electrical resistivity tomographies were obtained by using a robust inversion procedure to reduce the effect of possible data outliers in the resulting models. The effect on these models of different error estimations was also analyzed. Then, we built up a pseudo-3D model by laterally interpolating the 2D inversion results. Finally, by correlating the resulting model with the original plans, the remains of the expected main structures embedded in the site were characterized. In addition, an anomaly was identified that indicates the presence of a tunnel not previously reported.
\end{abstract}

Keywords: urban geophysics, electrical resistivity tomography, tunnels

(Some figures may appear in colour only in the online journal)

\section{Introduction}

The paper presented here is a case of a geophysical study at an urban site. This study was performed in the historical site named 'Manzana de las Luces', located in the old downtown of Buenos Aires, Argentina, which today is a highly populated area. This site is known as the birthplace of the intellectuality of the region. Its history began in 1661, with the settlement of Jesuits in the town (e.g. Furlong 1994). They planned and built up different buildings, including a church, a school, 


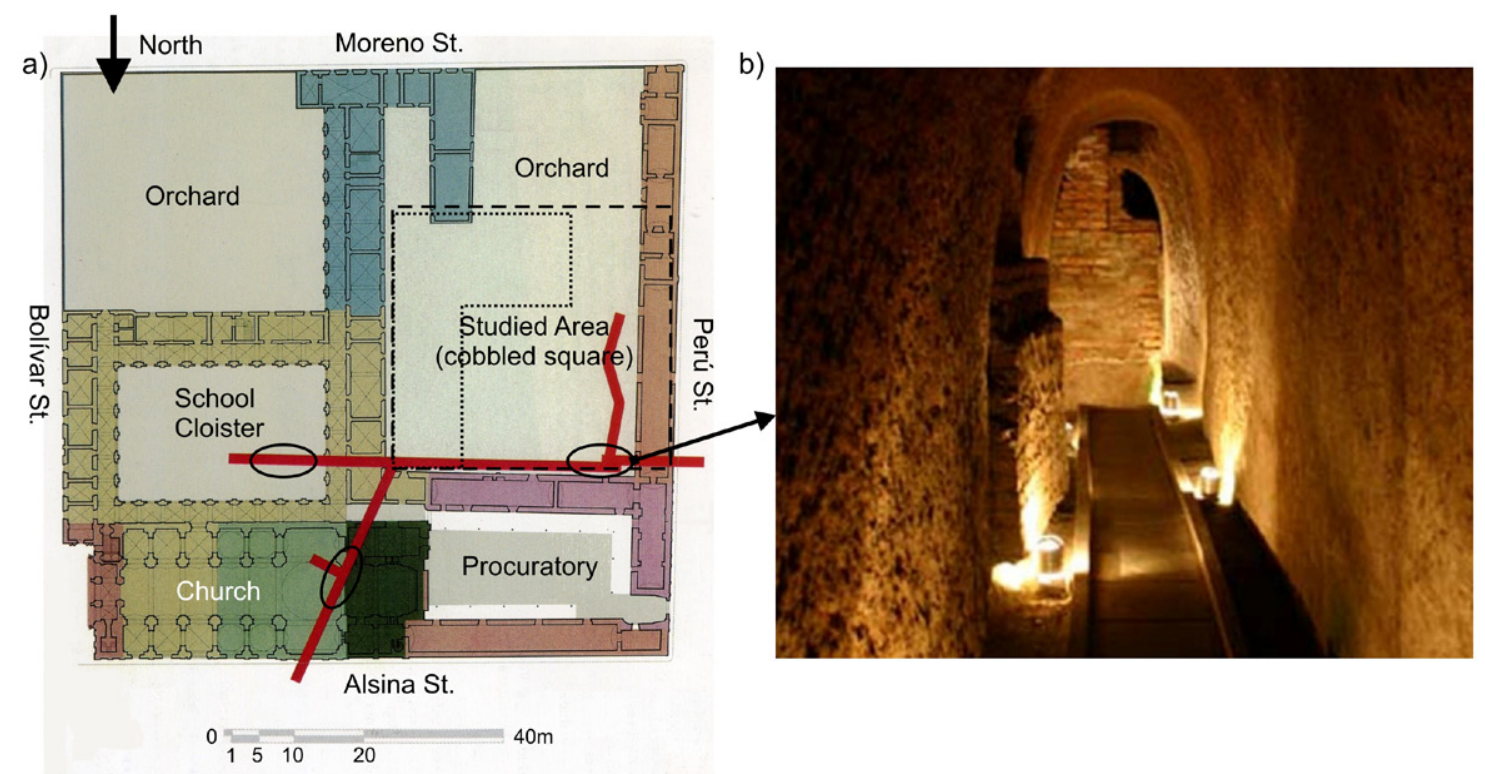

Figure 1. (a) Schematic plan of the site 'Manzana de las Luces', as it was during the Jesuit occupancy (1661-1730). The red lines indicate the location of the tunnels reported in historical records and the ellipses the sectors of these tunnels currently exposed. The dashed rectangle denotes the area studied in the present work (nowadays a cobbled square). The dotted lines show the limits of the basement of the old building of the Faculty of Sciences of the University of Buenos Aires, as described in a plan of 1895 (Mayochi et al 2008). (b) Photo of a tunnel restored and exposed.

cloisters and the procurator's offices. They also developed and maintained large orchards for the food supplies of the mission. During the 17th and 18th centuries tunnels were built in the downtown, forming a network linking churches and different public buildings with the Fort and the Customs of the town. According to historical records, at least three of them ran under the site of the mission (Mayochi et al 2008, Levinton 2012), one lying from east to west and two others approximately from north to south (figure 1(a)). Further historical investigations indicated that these tunnels could be longer and also that there could be others not officially reported. In the 19th century, the Faculty of Sciences of the University of Buenos Aires was built in a place previously occupied by an orchard, functioning until its demolition in 1973 (figure 1(a)). Then, this area became a cobbled square, which is now employed as a parking lot.

During the last years of the 20th century, a national project began to recover the cultural heritage of the site. Starting in 1983, tracts of the tunnels were located and conditioned for its reopening (figures 1(a) and (b)). A major objective in this project is to build up an interpretation center over the actual cobbled square, under the condition of preserving the historical remains, some of which will be later restored for exhibition. Within this context, we carried out a geophysical study with a primary goal of detecting and characterizing those buried structures.

Geophysical methods are increasingly being used to characterize archaeological remains and other subsurface structures in urban environments (e.g. Papadopoulos et al 2009, Batayneh 2011, Drahor 2011). These methods provide solutions to specific problems that arise with the advance of infrastructure modernization and urbanization and, due to its non-invasive character, are especially adequate for safeguarding cultural heritage.
Urban archaeogeophysics has its specific difficulties (Papadopoulos et al 2009, Batayneh 2011, Drahor 2011). The environmental noise in cities (electric, electromagnetic, vibrations, etc.) affects geophysical measurements. Besides, the access to the survey areas is often physically and/or timely limited by other uses, which generally restricts the amount of data that can be acquired. Regarding the archaeological structures, they are usually embedded in upper layers with intricate heterogeneities caused by later urban development. All these factors usually affect the quality of the data and the resolution of the obtained images, reducing the capability of identifying and characterizing these targets. Hence, at the beginning of each study, the available complimentary information (historical, geological, etc.) should be taken into account; then, different methods and/or methodologies should be explored to determine the most suitable based on the particular objectives and site conditions.

The geophysical methods most frequently applied for urban archaeological studies are ground penetrating radar (GPR) (e.g. Leucci and Negri 2006, Bonomo et al 2012), magnetic (e.g. Eppelbaum 2011), and electrical resistivity tomography (ERT) with measurements performed on surface and/or in boreholes (e.g. Tsokas et al 2011). These studies comprise, for instance, the detection of walls and cavities and the imaging of foundations. In some of them different techniques are combined, which usually provides greater reliability in the analysis of these complex environments (e.g. Negri and Leucci (2006), combined 2D ERT to study walls and cavities buried under and ancient temple and 3D GPR imaging to detect modern man-made structures, Drahor et al (2011), used magnetic gradiometry, GPR and ERT to define subsurface characteristics and search for possible structural damage in the subfloor of a church). Other geophysical techniques such 


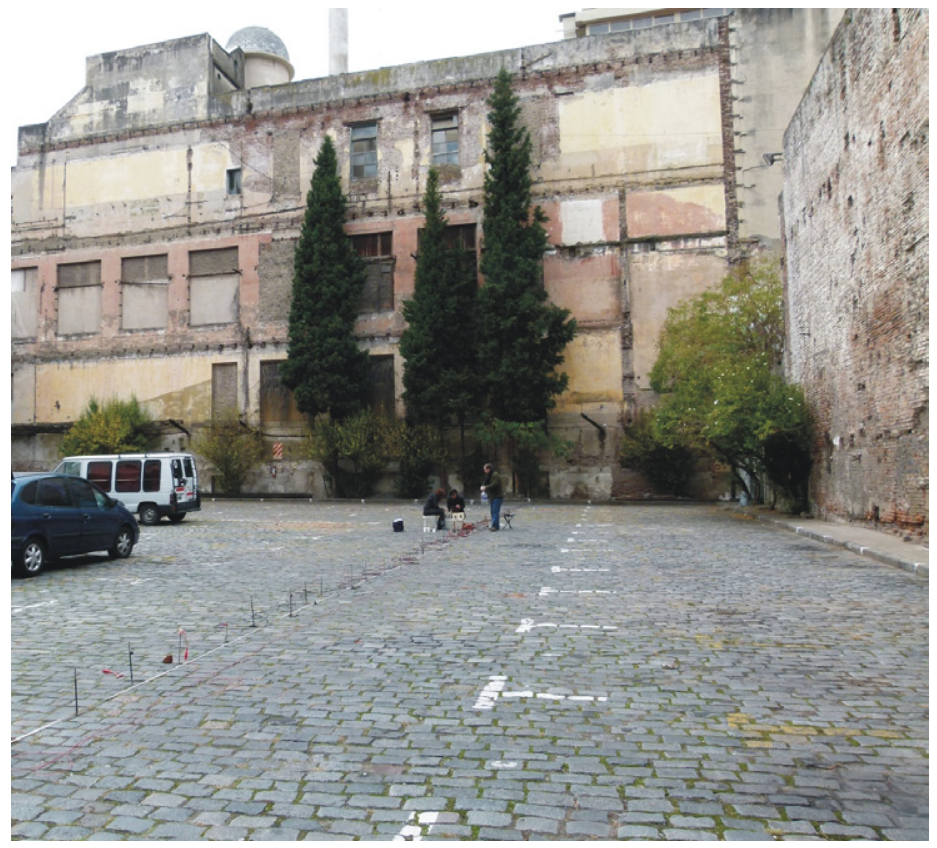

Figure 2. Photo of the cobbled square, initially being an orchard of the Mission, and from the last decade of the 19th century until 1973, the site of the Faculty of Sciences of the University of Buenos Aires (imprints can be seen on the front wall). A deployment of electrodes is also shown.

as seismic and microgravity are less used due to the difficulty to acquire this type of data in urban environments (Batayneh 2011, Drahor 2011).

Detecting tunnels is generally difficult, even more when they are placed in urban sites. GPR, gravity, ERT, electromagnetic induction (EMI) and seismic methods have been used for this task, alone or sometimes in combination, with varied effectiveness, depending on the characteristics of the soil and the contrast with the materials forming the tunnel, its depth and state of conservation, and the environmental conditions at the surface (e.g. Beetham and Hutchison 2009, De Franceschini and Marras 2010, Martinez-Lorenzo et al 2011, Orfanos and Apostolopoulos 2011, Tawfik et al 2011, Banks 2012).

Within this context, our main goals were to establish the actual trace and length of the N-S tunnel shown in figure 1(a) and to detect evidence of possible non-reported tunnels. An additional objective was to localize remains of the basement of the old building of the Faculty of Sciences (figure 1(a)). In the following, we describe the design of the geophysical survey, the data acquisition and processing procedures, and the obtained results. The anomalies detected in the ERT maps were interpreted in terms of possible buried archaeological features.

\section{Methodology for data acquisition and inversion}

The characteristics of the study area were challenging. Previous data from boreholes and archaeological test pits showed the presence of a complex urban stratigraphy with relocated architectural remains, in a rich organic soil with large percentages of silt and clay (Weissel 2010). Due to its appreciable content of clay, the soil was expected to have high electrical conductivity. Within this conductive host medium,

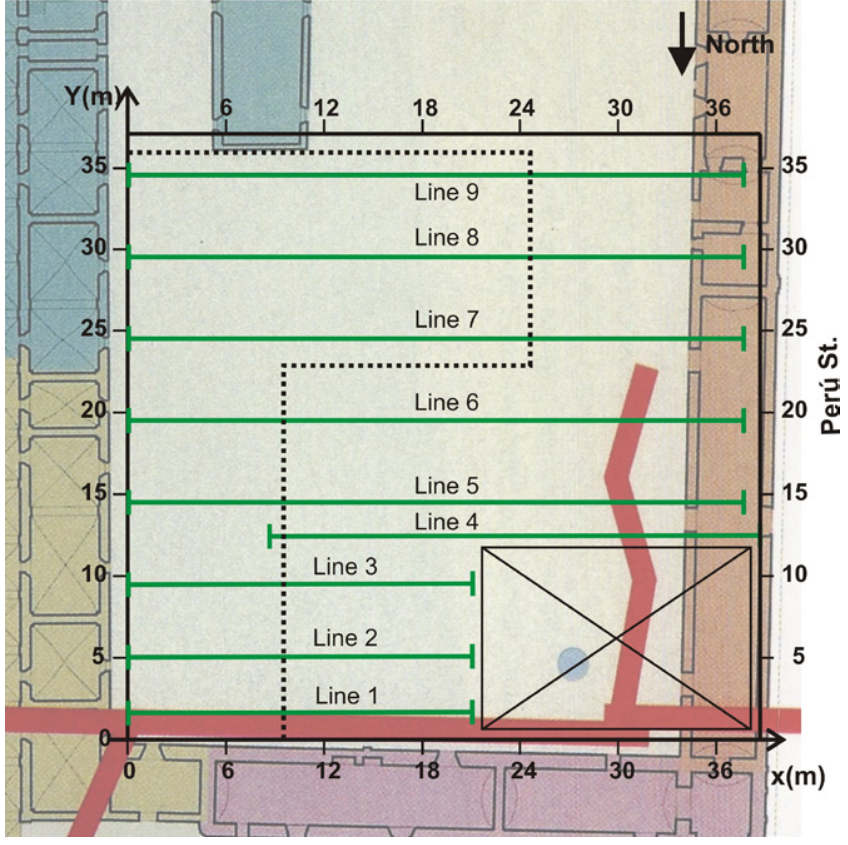

Figure 3. Location of the dipole-dipole profiles deployed in the cobbled square (studied area in figure 1(a). The crossed rectangle indicates a provisional construction. Like in figure 1(a), the red lines indicate the location of the tunnels reported in historical records and the dotted lines the limits of the old basement.

we looked for remains of the basement from the previous building (mainly composed of concrete and other resistive construction materials) and for tunnels, also resistive structures if they were not collapsed. The basement of the old building was expected to be located approximately $2-4 \mathrm{~m}$ deep; the exposed tunnel showed an approximate width of $1 \mathrm{~m}$ and was located about 3-4 $\mathrm{m}$ deep. In addition, we had to deal 
Table 1. Mean values of the percentage coefficients of variation of the measured apparent resistivities, for all the lines, electrode spacings and dipole separation factors.

\begin{tabular}{|c|c|c|c|c|c|c|c|c|c|c|c|c|}
\hline$a$ & $n$ & $z^{*}$ & Line 1 & Line 2 & Line 3 & Line 4 & Line 5 & Line 6 & Line 7 & Line 8 & Line 9 & Mean \\
\hline 1.5 & 1 & -0.624 & 0.235 & 0.193 & 0.143 & 0.197 & 0.109 & 0.152 & 0.120 & 0.184 & 0.194 & 0.170 \\
\hline 1.5 & 2 & -1.046 & 0.915 & 0.544 & 0.425 & 0.257 & 0.376 & 0.221 & 0.242 & 0.348 & 0.336 & 0.407 \\
\hline 1.5 & 3 & -1.443 & 1.130 & 0.398 & 0.516 & 0.337 & 0.365 & 0.689 & 0.322 & 0.301 & 0.790 & 0.539 \\
\hline 1.5 & 4 & -1.830 & 1.040 & 0.420 & 0.395 & 0.657 & 0.800 & 1.280 & 0.707 & 0.652 & 0.891 & 0.760 \\
\hline 1.5 & 5 & -2.214 & 2.650 & 0.851 & 0.728 & 1.580 & 2.490 & 3.820 & 0.784 & 1.160 & 2.440 & 1.830 \\
\hline 1.5 & 6 & -2.595 & 5.200 & 1.940 & 2.790 & 3.250 & 4.490 & 5.770 & 1.600 & 2.500 & 5.800 & 3.700 \\
\hline 1.5 & 7 & -2.975 & 5.480 & 3.230 & 2.640 & 3.450 & 5.600 & 6.850 & 2.070 & 2.320 & 6.870 & 4.280 \\
\hline 1.5 & 8 & -3.354 & 6.940 & 4.910 & 5.380 & 8.050 & 9.640 & 7.550 & 3.900 & 7.200 & 8.570 & 6.900 \\
\hline 1.5 & 9 & -3.734 & & & & 5.760 & 8.520 & 4.840 & 4.670 & 7.970 & 7.830 & 6.600 \\
\hline 1.5 & 10 & -4.110 & & & & 4.280 & 7.070 & 6.390 & 8.090 & 7.790 & 12.20 & 7.640 \\
\hline 3 & 1 & -1.248 & 0.339 & 0.252 & 0.371 & 0.195 & 0.258 & 0.322 & 0.255 & 0.329 & 0.193 & 0.279 \\
\hline 3 & 2 & -2.091 & 0.352 & 0.462 & 0.547 & 0.362 & 0.629 & 0.392 & 0.287 & 0.392 & 0.279 & 0.411 \\
\hline 3 & 3 & -2.886 & 1.580 & 3.020 & 4.140 & 1.320 & 2.400 & 2.530 & 0.843 & 0.917 & 1.790 & 2.060 \\
\hline 3 & 4 & -3.660 & 5.480 & 5.900 & 7.830 & 3.300 & 3.140 & 6.170 & 1.590 & 1.480 & 2.630 & 4.170 \\
\hline 3 & 5 & -4.428 & 4.580 & 3.190 & 9.600 & 6.940 & 4.730 & 8.600 & 5.560 & 2.310 & 9.700 & 6.130 \\
\hline 3 & 6 & -5.190 & & & & 6.980 & 5.690 & 9.560 & 10.50 & 4.370 & 11.10 & 8.030 \\
\hline 3 & 7 & -5.949 & & & & 10.50 & 10.60 & 9.740 & 14.00 & 9.010 & 13.60 & 11.20 \\
\hline Mean & & & 2.760 & 1.950 & 2.730 & 3.380 & 3.940 & 4.400 & 3.270 & 2.900 & 5.010 & 3.450 \\
\hline
\end{tabular}

Note: $z^{*}$ denotes the median depth of investigation (following Edwards 1977).

with high environmental electromagnetic noise, and with the characteristics of the rough surface, covered by cobblestones (figure 2).

Considering this, we performed a pre-feasibility study to determine the usefulness of different geophysical methods. We made tests using three different methods: ERT, GPR and EMI.

For the electromagnetic induction measurements we used a small-loop, multifrequency EMI system GEM-2 (Geophex). This equipment works in a frequency range between 300 and $96000 \mathrm{~Hz}$, and has an intercoil separation of $1.66 \mathrm{~m}$; so it could provide the required penetration depth. Nevertheless, no useful information was obtained from these data because they were highly contaminated by environmental electromagnetic noise.

Then, we used a PulseEkko Pro GPR system (Sensors and Software Inc.), with shielded antennas of 250 and $500 \mathrm{MHz}$. Usually, GPR has good potential for providing high resolution images; however, the usefulness of GPR over most of the urban area of Buenos Aires has been very limited due to the high clay content in soil composition, and its large humidity. For this particular case, the obtained data showed strong attenuation. The soil strongly absorbed the signals in the used frequency range, and this reduced the penetration depth for both antennas, $500 \mathrm{MHz}$ and $250 \mathrm{MHz}$, to about $0.60 \mathrm{~m}$ and $1.2 \mathrm{~m}$, respectively. The use of $100 \mathrm{MHz}$ antennas, as they were unshielded, produced noisy data without the required resolution.

Regarding the geoelectrical measurements, we had to determine the best way to make the electrode contact with the surface. There were different possibilities; the use of flat base electrodes that do not need to be nailed down (Tsokas et al 2008), the use of capacitive contacts (Dabas et al 2000, Bongiovanni and de la Vega 2006, Osella et al 2012) or the use of usual galvanic contact electrodes placed in holes making contact with the soil underneath the surface obstacle, or even used for borehole measurements (e.g. Tsokas et al 2011). The first two were discarded due to the irregular shape of the cobblestone surface where the study was performed. The last possibility had to be disregarded due to its invasive nature and the historical status of the site. Therefore, the third technique was used taking advantage of the space between the cobblestones (about $1.5 \mathrm{~cm}$ ) to place the electrodes.

For these measurements, data were acquired using Saris 500 equipment (Scintrex). The electrodes were placed inbetween the cobbles (see figure 2). We performed different tests and found that, in general, good electrode contact and a stable injection of current could be achieved by burying the electrodes at least $15 \mathrm{~cm}$ deep, to overcome the cobblestone cover. Due to the high conductivity of the material beneath the cobblestones in some zones of the studied area, we had to limit the current injection between a minimum of $10 \mathrm{~mA}$ and a maximum of $50 \mathrm{~mA}$ to prevent equipment malfunction. Hence, a high stacking (about 15) was used in order to reduce data noise.

Several studies comparing the advantages and limitations of different electrode arrays (e.g. Dahlin and Zhou 2004, Martorana et al 2009, Szalai et al 2011) revealed that, in noisy environments, the dipole-dipole configuration can provide comparatively good penetration depth and one of the best imaging resolutions. In addition, our previous experience also indicated the usefulness of this configuration for archaeological prospecting (Martino et al 2005, Osella et al 2005, Bonomo et al 2012). On this basis, we decided to utilize the dipole-dipole configuration for this study. We deployed nine E-W profiles (figure 3), approximately perpendicular to the known N-S tunnel. Taking into account the expected characteristics of the targets, electrode spacings $a=1.5$ and $3 \mathrm{~m}$ were selected, with dipole separation factors $(n)$ up to $n=8$ and 5 , for Lines 1-3, and $n=10$ and 7, for Lines 4-9, respectively. The separation between the profiles was approximately $5 \mathrm{~m}$. 


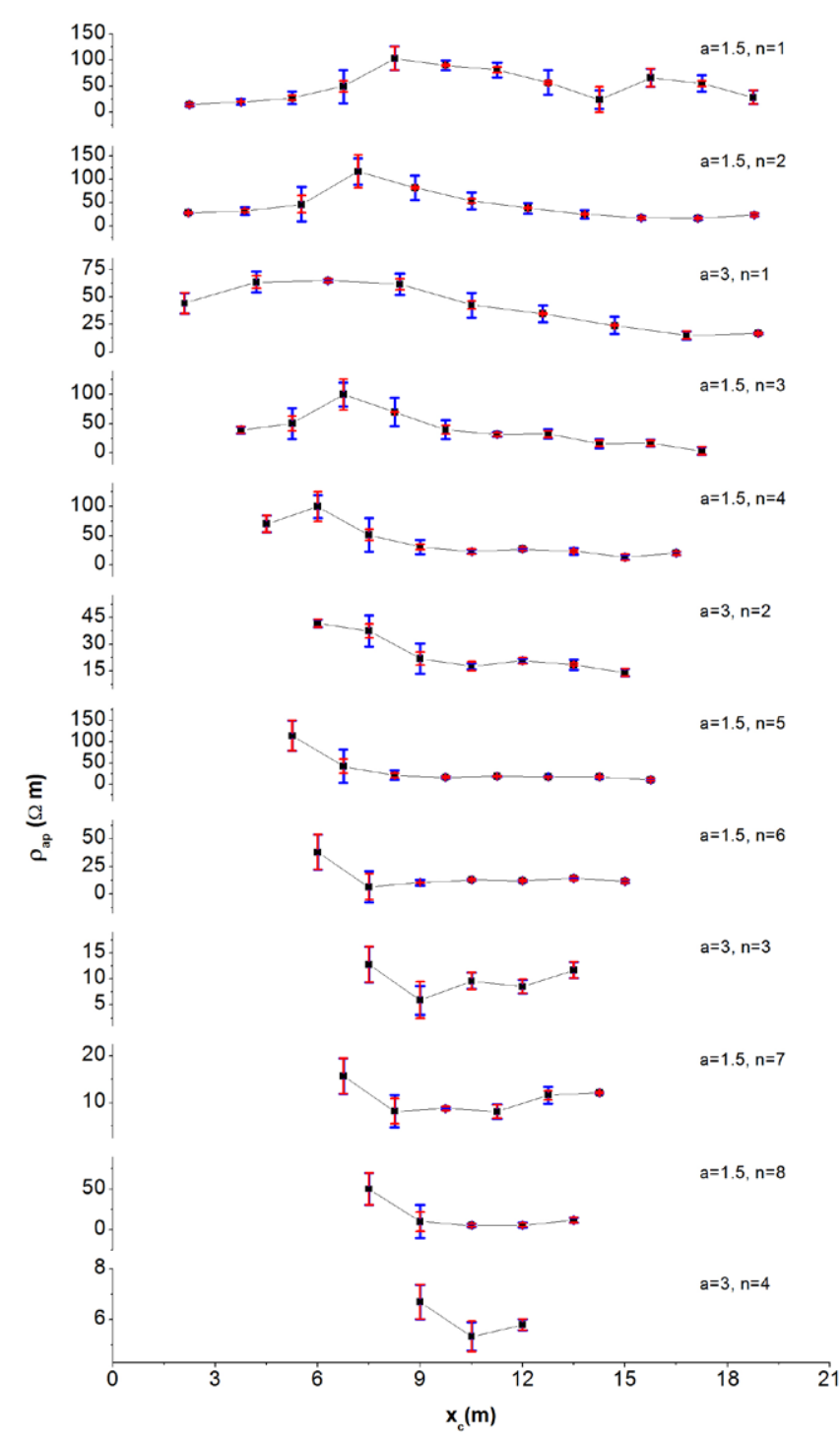

Figure 4. Apparent resistivity data $\left(\rho_{a p}\right)$ acquired along line 3 , with electrode spacings $a=1.5 \mathrm{~m}$ and $3 \mathrm{~m}$, and dipole separation factors up to $n=8$ and 4 , respectively. $X_{c}$ denotes the $x$ position of the center of the electrodes in each measurement. The error estimations $\varepsilon_{\mathrm{SD} 3}$ and $\varepsilon_{\mathrm{DM} 3}$, obtained from equations (1) and (3), are indicated by blue and red error bars, respectively.

Their position was optimized considering parking lot operation. The time was very restrictive, since the area for each profile could be freed from cars only for short periods of time.

From the repeated measurements performed at each point, the standard deviation of each apparent resistivity data and its percentage coefficient of variation, were obtained. This provided an estimation of the random errors of this magnitude. Table 1 shows the mean values of these coefficients of variation, for all the lines, electrode spacings and $n$ values. As can be observed, the values are acceptable considering the characteristics of the site. However, this did not guarantee data quality. As it is well known (e.g. Zhou and Dahlin 2003, Loke et al 2013), outlier data points (those arising from nonrandom sources of error such as bad electrode contact, electrode polarization, or equipment malfunction) can have low coefficients of variation.

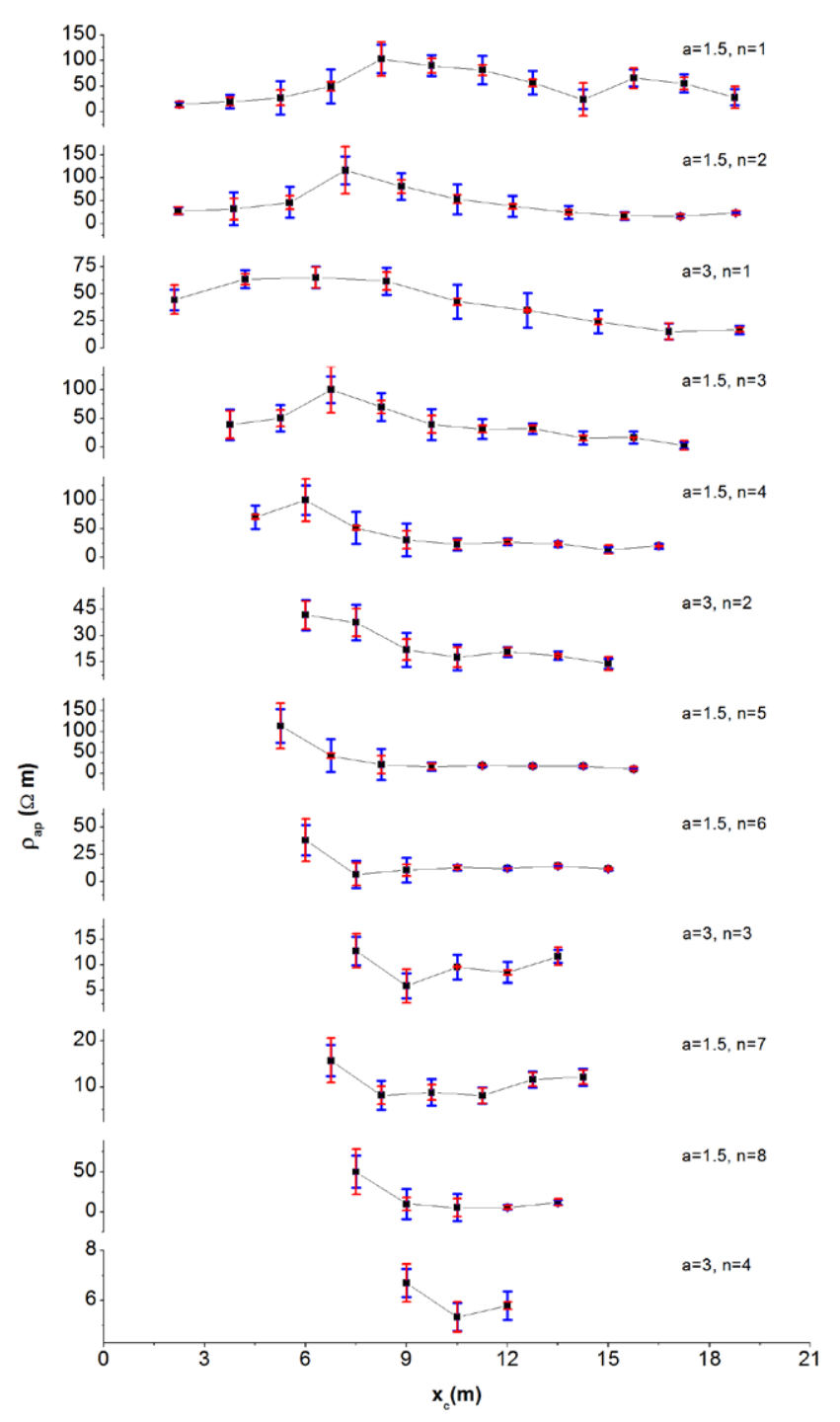

Figure 5. The same as in figure 4, but considering the error estimations $\varepsilon_{\mathrm{SD} 5}$ (blue error bars) and $\varepsilon_{\mathrm{DM} 5}$ (red error bars) that were calculated using equations (2) and (4), respectively.

One manner to obtain more accurate error estimations, which include the described non-random effects, is to perform reciprocal measurements (Parasnis 1988, Park and Van 1991). We could not apply this method, because that would have required almost a duplication of the time required for data acquisition. Instead, four different error estimations, $\varepsilon_{\mathrm{SD} 3}, \varepsilon_{\mathrm{SD} 5}, \varepsilon_{\mathrm{DM} 3}$ and $\varepsilon_{\mathrm{DM} 5}$, were calculated using the alternative methodology described next.

If $\rho_{a p i j k l}$ is the apparent resistivity measured at the position of the center of the electrodes $x_{c i}$, along line $j$, with the electrode spacing $a_{k}$ and the dipole separation factor $n_{l}$, then:

$$
\begin{gathered}
\varepsilon_{\mathrm{SD} 3}\left(\rho_{a p i j k l}\right)=\operatorname{SD}\left(\rho_{a p(i-1) j k l}, \rho_{a p i j k l}, \rho_{a p(i+1) j k l}\right) \\
\varepsilon_{\mathrm{SD} 5}\left(\rho_{a p i j k l}\right) \\
=\operatorname{SD}\left(\rho_{a p(i-2) j k l}, \rho_{a p(i-1) j k l}, \rho_{a p i j k l}, \rho_{a p(i+1) j k l}, \rho_{a p(i+2) j k l}\right) \\
\varepsilon_{\mathrm{DM} 3}\left(\rho_{a p i j k l}\right)=\left|\rho_{a p i j k l}-\operatorname{AVG}\left(\rho_{a p(i-1) j k l}, \rho_{a p i j k l}, \rho_{a p(i+1) j k l}\right)\right|
\end{gathered}
$$


Table 2. Values of the main inversion parameters that provided the best 2D ERTs.

\begin{tabular}{ll}
\hline Initial damping factor & 0.3 \\
Minimum damping factor & 0.03 \\
RMS convergence limit & $2 \%$ \\
Vertical to horizontal flatness filter ratio & 1 \\
Number of nodes between adjacent electrodes & 4 \\
Type of Jacobian matrix calculation & Gauss-Newton \\
Data constrain & Robust \\
Cutoff factor for robust data constrain & 0.05 \\
Model constrain & Robust \\
Cutoff factor for robust model constrain & 0.005 \\
Extended model & No \\
Reduce the effectof side blocks & Severe \\
Forward modeling method & Finite Elements \\
Type of mesh & Finest \\
Width of blocks & Normal \\
Blocks have the same width & Yes \\
Logarithm of apparent resistivity & Yes \\
Type of reference resistivity & Average \\
Model refinement & Half-width cells \\
Type of optimization method & Gauss-Newton \\
Data errors present & No \\
\hline
\end{tabular}

$$
\begin{aligned}
& \varepsilon_{\mathrm{DM} 5}\left(\rho_{a p i j k l}\right) \\
& \quad=\left|\rho_{a p i j k l}-\operatorname{AVG}\left(\rho_{a p(i-2) j k l}, \rho_{a p(i-1) j k l}, \rho_{a p i j k l}, \rho_{a p(i+1) j k l}, \rho_{a p(i+2) j k l}\right)\right|
\end{aligned}
$$

where SD and AVG refer to the standard deviation and the average of the indicated apparent resistivity data, respectively. $\varepsilon_{\mathrm{SD} 3}$ and $\varepsilon_{\mathrm{SD} 5}$ denote the error estimations of the datum $\rho_{a p i j k l}$ obtained by calculating the standard deviation of the apparent resistivity considering 3 and 5 neighboring measurement points, respectively, while $\varepsilon_{\mathrm{DM} 3}$ and $\varepsilon_{\mathrm{DM} 5}$ name the error estimations of the datum $\rho_{a p i j k l}$ obtained by calculating the absolute deviation of this datum from the mean apparent resistivity of 3 or 5 neighboring points, respectively.

These error estimations comprise measurements corresponding to different electrode positions, which could have, for instance, different contact resistances or electrode polarization values. Thus, when the resistivity of the subsurface material is nearly uniform, they may provide a good estimation of both the random and non-random errors. In other cases, because the effect caused by the variations in the subsurface resistivity (especially the lateral variations) is also included, values can be considered upper limits of the error estimations.

As an example, figure 4 shows the apparent resistivity data corresponding to line 3 , with the error estimations $\varepsilon_{\mathrm{SD} 3}$ and $\varepsilon_{\mathrm{DM} 3}$ indicated. The same data, with the error estimations $\varepsilon_{\mathrm{SD} 5}$ and $\varepsilon_{\mathrm{DM} 5}$, are shown in figure 5 . On the whole, these errors were greater than the standard deviation of these data. According to their definition, for each electrode spacing $a_{k}$ and dipole separation factor $n_{l}, \varepsilon_{\mathrm{SD} 3}$ and $\varepsilon_{\mathrm{DM} 3}$, or $\varepsilon_{\mathrm{SD} 5}$ and $\varepsilon_{\mathrm{DM} 5}$, were similar when the apparent resistivity at point $x_{c i}$ was a local maximum or minimum; otherwise, $\varepsilon_{\mathrm{SD} 3}$ and $\varepsilon_{\mathrm{SD} 5}$ were greater than $\varepsilon_{\mathrm{DM} 3}$ and $\varepsilon_{\mathrm{SD} 5}$, respectively.

For the inversions, we used the codeRES2DINV, version 3.59.119 (Loke and Barker 1996). For each profile, the data

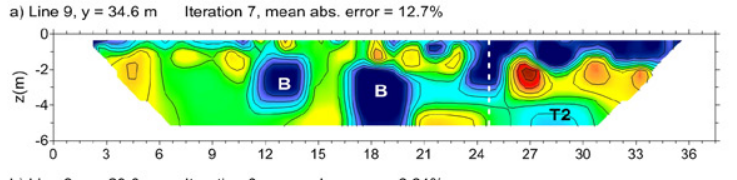

b) Line $8, y=29.6 \mathrm{~m}$ Iteration 6 , mean abs. error $=6.64 \%$

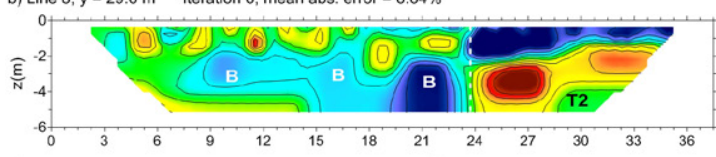

c) Line $7, y=24.6 \mathrm{~m}$ Iteration 7 , mean abs. error $=6.05 \%$

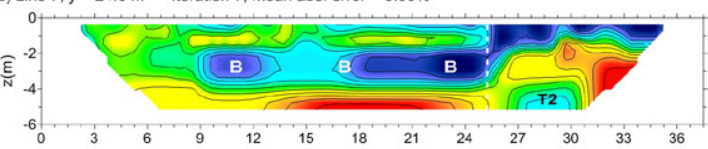

d) Line $6, y=19.6 \mathrm{~m}$ Iteration 5 , mean abs. error $=13.0 \%$

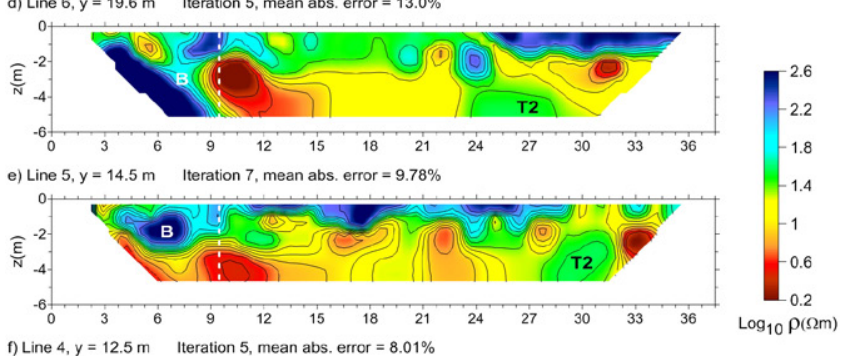

f) Line $4, y=12.5 \mathrm{~m}$ Iteration 5 , mean abs. error $=8.01 \%$
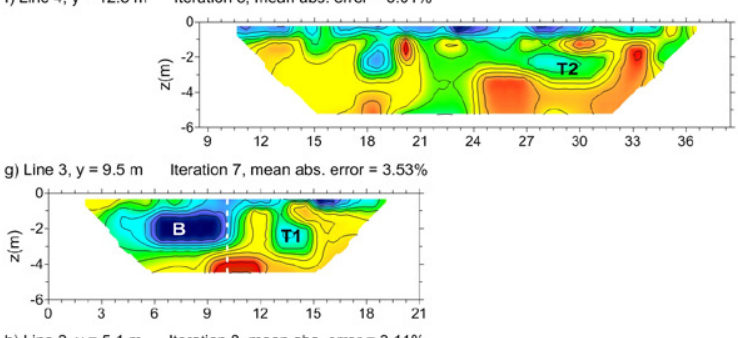

h) Line $2, y=5.1 \mathrm{~m} \quad$ Iteration 8 , mean abs. error $=3.11 \%$

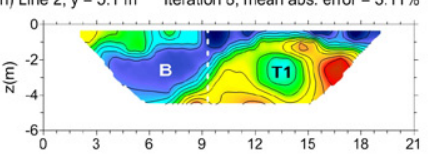

Line $1, y=1.7 \mathrm{~m} \quad$ Iteration 9 , mean abs. error $=3.92 \%$

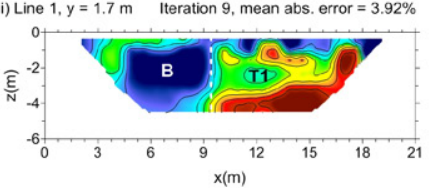

Figure 6. (a) to (i) Electrical resistivity tomographies obtained from the 2D inversion of the dipole-dipole profiles acquired along lines 1 to 9 , respectively, as shown in figure 3. These inversions were performed with the code RES2DINV (Loke and Barker 1996), using robust data and model constrains, and without providing any error estimations (see table 2). The anomaly named B indicates zones with resistive materials that could correspond to remains of the basement of the old building. The limits of these zones are indicated by dashed white lines. The anomalies T1 and T2 probably correspond to stretches of tunnels.

acquired with both electrode spacings ( $a=1.5$ and $3 \mathrm{~m}$ ) were inverted together to improve both the resolution and penetration depth of the models.

In addition to the usual least-squares (L2 norm) inversion, this program offers a robust inversion option in which the absolute values (L1 norm) of the data misfit are minimized (Loke et al 2003). We selected this robust data constrain option for all the inversions, because it allows reducing the effect of data outliers in the resulting models. 


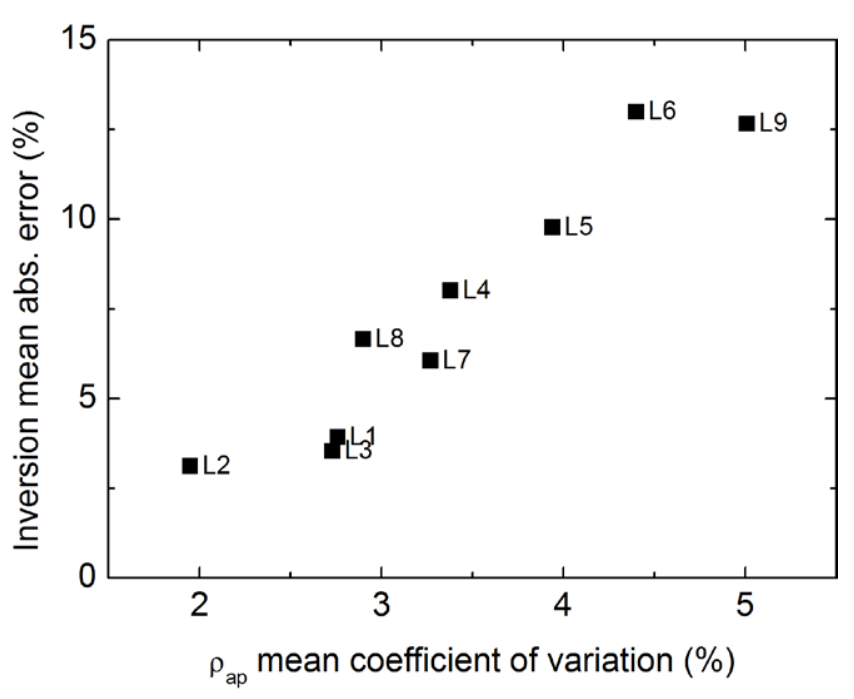

Figure 7. Mean absolute errors of the inversions shown in figure 6, plotted against the mean value of the coefficients of variation of the apparent resistivity along the corresponding line (which are listed in the last row of table 1). L1-L9 denote the lines 1-9, respectively.

Regarding model constrains, the square (L2 norm) and the absolute (L1 norm) changes in the model resistivity values were alternatively minimized. As it is well known, the first procedure generates models with smooth resistivity variations. On the other hand, the robust model constrain tends to produce 'blocky' models, with sharp interfaces between regions with approximately constant resistivity. The best results were obtained with this last procedure, which is comprehensible, considering that the described blocky models were more consistent with the subsurface structure expected in the site. Table 2 lists the values of the main parameters used to obtain the final ERTs.

These inversions were first performed without providing to the program any information about data errors. This is a common approach, since in many cases accurate error estimations are not available. Then, in order to investigate the reliability of the anomalies detected in the final models, the inversions were repeated using the same parameters as in table 2 , but considering the error estimations $\varepsilon_{\mathrm{SD} 3}, \varepsilon_{\mathrm{SD} 5}, \varepsilon_{\mathrm{DM} 3}$ and $\varepsilon_{\text {DM5 }}$, defined by equations (1)-(4).

The separation of the profiles (about $5 \mathrm{~m}$ ) prevented the performance of a 3D inversion. As an alternative, we generated a pseudo-3D model of the subsurface by combining the 2D inversion results. Model resistivities obtained for all the lines at each $z$ value were interpolated in the $x-y$ plane, using a kriging method with a linear variogram. Then, those constant-depth slices were plotted, to better visualize the alignment of the anomalies.

\section{Results}

The ERTs obtained from the 2D inversion of the nine dipoledipole profiles are shown in figure 6. These inversions were performed applying robust data and model constrains, and without providing any estimation of data errors (see table 2). The achieved mean absolute errors are reasonable, taking into account the difficulties encountered for data acquisition and

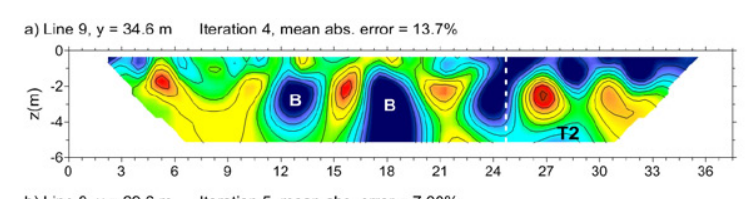

b) Line $8, y=29.6 \mathrm{~m} \quad$ Iteration 5 , mean abs. error $=7.00 \%$

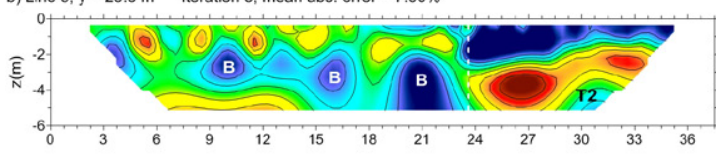

c) Line $7, y=24.6 \mathrm{~m}$ Iteration 4 , mean abs. error $=6.95 \%$

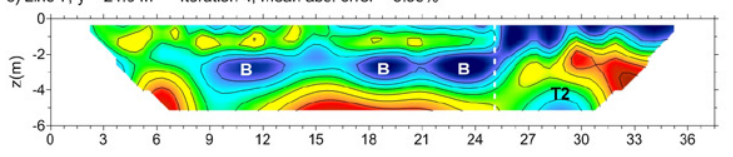

d) Line $6, y=19.6 \mathrm{~m}$ Iteration 5 , mean abs. error $=11.4 \%$

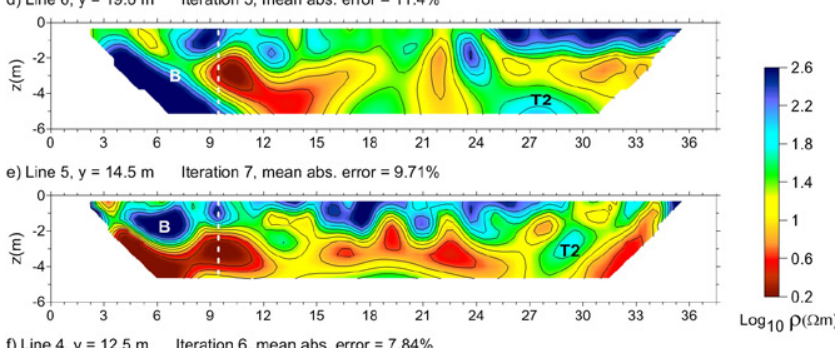

f) Line $4, y=12.5 \mathrm{~m}$ Iteration 6 , mean abs. error $=7.84 \%$
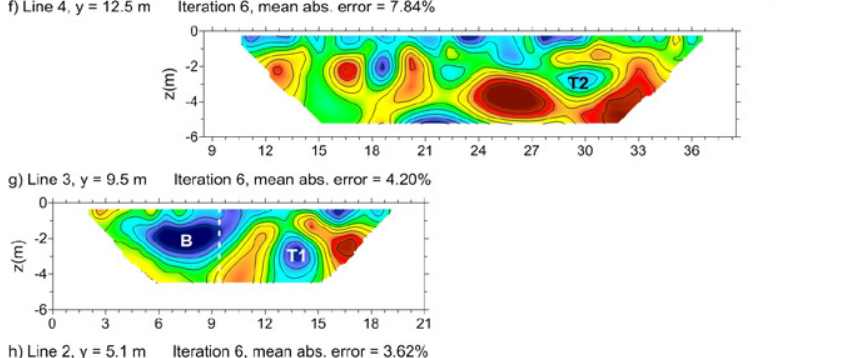

h) Line $2, y=5.1 \mathrm{~m} \quad$ Iteration 6 , mean abs. error $=3.62 \%$
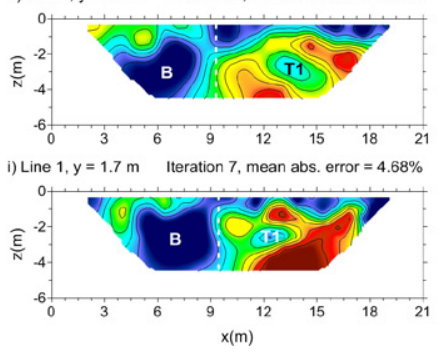

Figure 8. (a) to (i) Electrical resistivity tomographies corresponding to lines 1 to 9 , respectively, obtained using robust data constrains, but smooth model constrains. The rest of the inversion parameters had the same values as in the inversions shown in figure 6 (listed in table 2). Again, no error estimations were provided. The anomalies $\mathrm{B}, \mathrm{T} 1$ and $\mathrm{T} 2$ are also clearly observable in these models. Their resistivities are somewhat different than in the former case, but their localization is similar.

the complexity of the subsurface structure. Another indicator that the data were neither over nor under fitted is that, although no error estimations were provided for the inversions, the attained mean absolute errors exhibit a clear correlation with the mean value of the percentage coefficients of the variation of the apparent resistivity along each line (figure 7).

Different structures can be identified in the models shown in figure 6 . The conductive matrix has resistivity values close to $10 \mathrm{ohmm}$. Zones containing highly resistive materials (resistivity about $100-300 \mathrm{ohmm}$ ) are found in most of the profiles (anomaly named B). These zones were associated to 
the remains of the basement of the old building of the Faculty of Sciences; the limits of these zones are indicated by dashed white lines in figure 6 . In addition, there are other types of anomalies, named T1 and T2, which appear as localized structures more resistive than their surroundings. The centers of the anomaly T1, appearing in lines 1-3, are located at $x$ between $12-14 \mathrm{~m}$ and $z=2.5-3 \mathrm{~m}$, approximately. The anomaly $\mathrm{T} 2$ is centered at $x=27-30 \mathrm{~m}$; its depth is similar to that of $\mathrm{T} 1$ in line 4, and increases towards the south. In lines 6-9, the top of this anomaly is located about $4 \mathrm{~m}$ deep. Considering its characteristics and localization, T2 possibly corresponds to the $\mathrm{N}-\mathrm{S}$ tunnel reported in the historical records, and shown in figures 1(a) and 3. In this case, this tunnel would continue towards the south throughout all the studied area. T1 could correspond to a stretch of a non-declared tunnel, which should be connected with the main E-W tunnel.

The ERTs obtained using smooth instead of robust model constrains are shown in figure 8 , for comparison with the results displayed in figure 6 . Once more, no error estimations were provided; the rest of the inversion parameters had the same values as in the previous inversions. The most relevant result is that the anomalies $\mathrm{B}, \mathrm{T} 1$ and $\mathrm{T} 2$ are also clearly observable in these models. Their resistivity values are somewhat different, but their localization is almost the same. The attained mean absolute errors are also similar to the former case.

The ERTs shown in figures 6 and 8 were obtained without including the errors. To analyze the effects of the errors on the final models, we repeated the inversions including the error estimations calculated according equations (1)-(4), respectively. Figure 9 shows the models obtained for line 3 using these error estimations; the rest of the inversion parameters are those listed in table 2. Figure $6(\mathrm{~g})$ is included at the top, for an easier comparison. Figures 10 and 11 show the analogous results, for lines 5 and 7 , respectively. As the variations in the subsurface resistivity were appreciable along the three lines (figures 9(a), 10(a) and 11(a), or 6(g), (e) and (c), respectively), according to what was explained in the last section, the error estimations used, $\varepsilon_{\mathrm{SD} 3}, \varepsilon_{\mathrm{SD} 5}, \varepsilon_{\mathrm{DM} 3}$ and $\varepsilon_{\mathrm{DM} 5}$, were probably significantly greater than actual data errors. Even so, the anomaly B is still clearly detectable in all the models obtained for the three lines, and $\mathrm{T} 1$ is detectable in all the models corresponding to line 3 . With regards to $\mathrm{T} 2$, the loss of detectability is greater in line 7 than in line 5. Two probable reasons for this are that, on one side, T2 is deeper in line 7, and that, on the other side, the variability of the subsurface resistivity in the zone near T2 is greater in line 7 (figures 6(c) and (e), or 10(a) and 11(a), respectively), thus, the overestimation of the errors possibly was greater.

Having tested the reliability of the resulting models, we then analyzed the correlation of the anomalies along the different profiles. As explained in the last section, by combining the results of the 2D inversions shown in figure 6, we generated a pseudo-3D model of the subsurface. This procedure had provided very useful results in a previous work, where it contributed to the detection of linear anomalies associated to the remains of a Spanish fort from the 16th century (Bonomo et al 2012). a) No error estimations

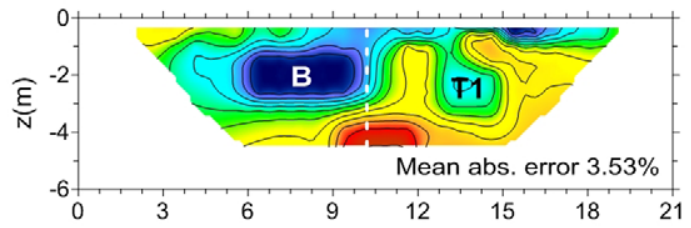

b) Error estimations $\varepsilon_{\mathrm{SD} 3}$, calculated from Eqn. 1

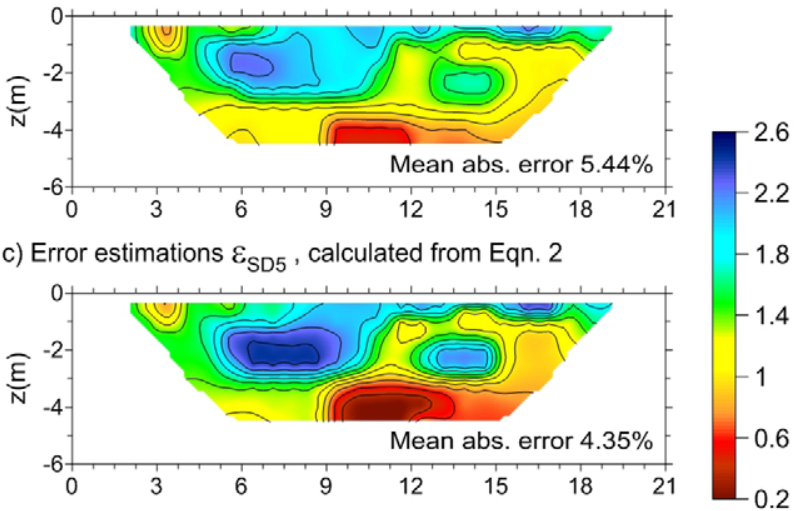

d) Error estimations $\varepsilon_{\mathrm{DM} 3}$, calculated from Eqn. $3 \quad \log _{10} \rho(\Omega \mathrm{m})$

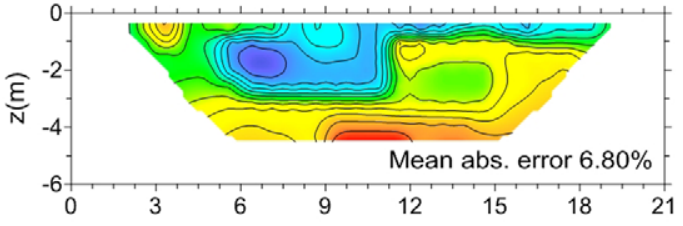

e) Error estimations $\varepsilon_{D M 5}$, calculated from Eqn. 4

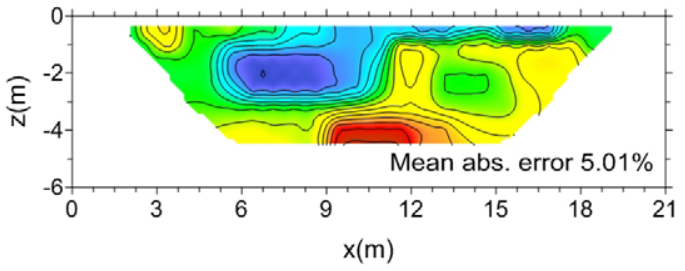

Figure 9. Models obtained for the Line 3, after 7 iterations, using the same inversion parameters as for the inversion shown in figure 6. The upper model (a) is the same as the one shown in figure $6(\mathrm{~g})$. The rest of the models (b to e) were obtained considering different error estimations. All of them have lower resolutions than (a), but the anomalies B and T1 are still detectable in all the cases.

Constant-depth slices of this pseudo-3D model are shown in figure 12.The localization of the anomalies $\mathrm{T} 1$ and $\mathrm{T} 2$, according to the ERTs shown in figure 6, and the limits of the old basement according to the plan of 1895 (figures 1(a) and 3 ), are superimposed for comparison. The zone occupied by remains of the basement, associated with resistive anomaly B, appears clearly delineated, at depths ranging from about 2-3.5 $\mathrm{m}$. The depth, approximate localization and general alignment of the resistive anomaly $\mathrm{T} 2$ are close to the ones expected for the N-S tunnel (figures 1(a) and 3), which, according to these results, would extend southwards beyond what was previously reported. Regarding the anomaly T1, observed at depths between 2-3.5 m, comparing its features with $\mathrm{T} 2$, we earlier proposed the existence of another tunnel, not previously known. The NNE-SSW orientation of this tunnel can be clearly appreciated in this figure. This structure is not detected for $y>10 \mathrm{~m}$. 


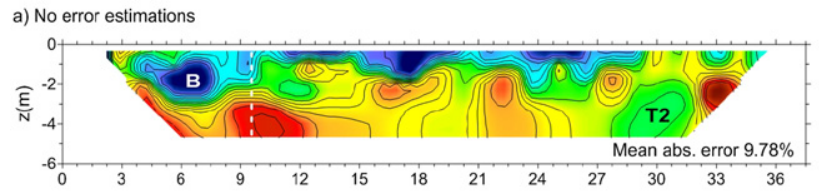

b) Error estimations $\varepsilon_{\mathrm{SD} 3}$, calculated from Eqn. 1
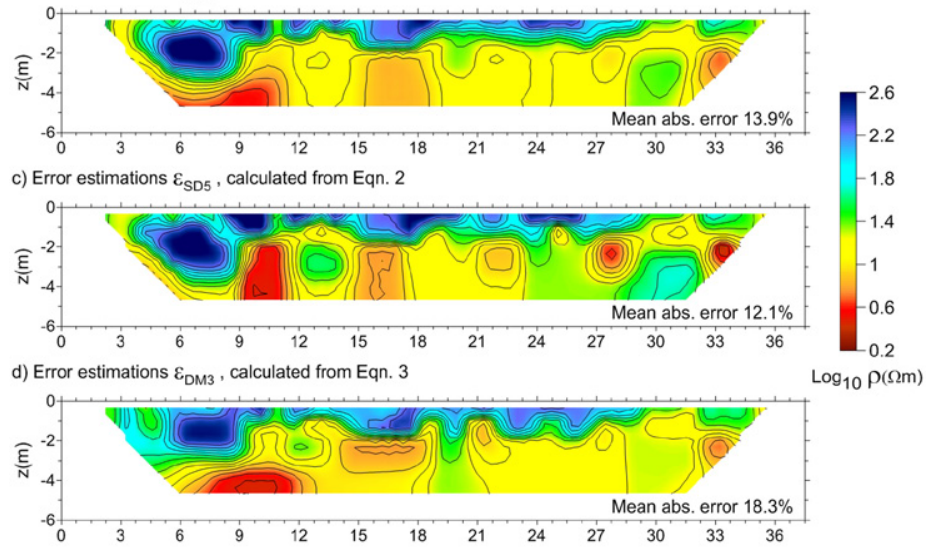

e) Error estimations $\varepsilon_{\mathrm{DM} 5}$, calculated from Eqn. 4

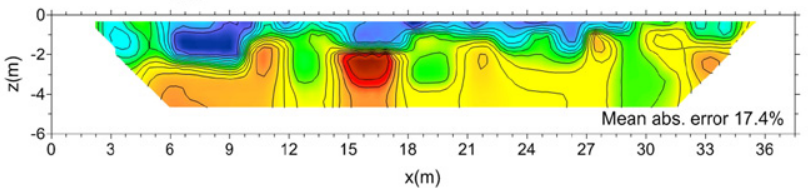

Figure 10. The same as in figure 9 for the line 5. In this case, the upper model (a) is the same as the one shown in figure 6(e). The anomaly $\mathrm{T} 2$ is detectable in all the models (b to e, respectively) the lowest resolution corresponds to the error estimations $\varepsilon_{\mathrm{DM} 3}$ (d).

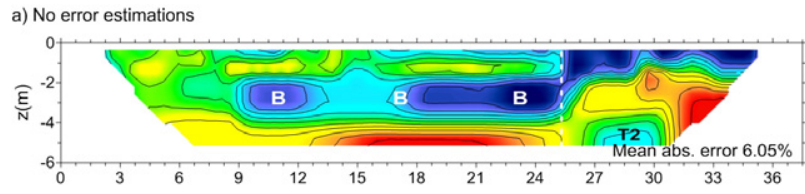

b) Error estimations $\varepsilon_{\mathrm{SD} 3}$, calculated from Eqn. 1
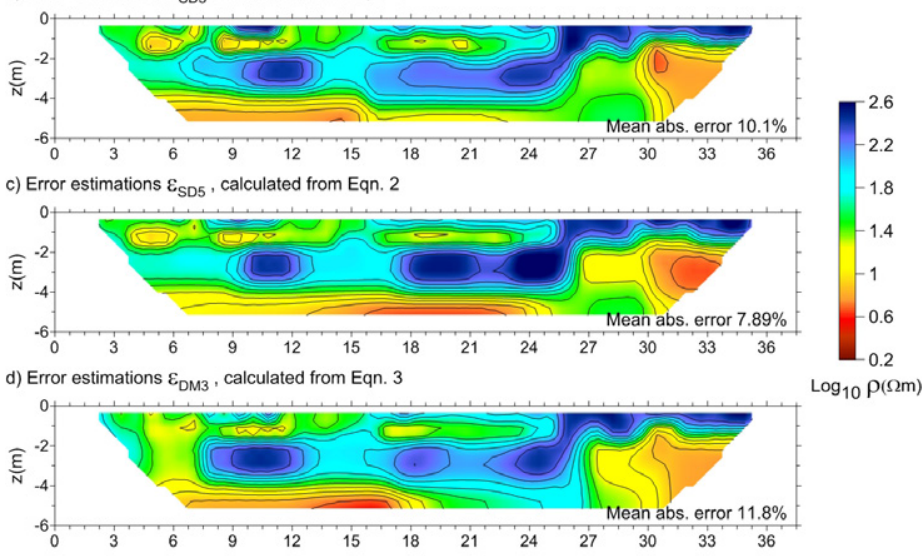

$\log _{10} \rho(\Omega m)$

e) Error estimations $\varepsilon_{\mathrm{DM} 5}$, calculated from Eqn. 4

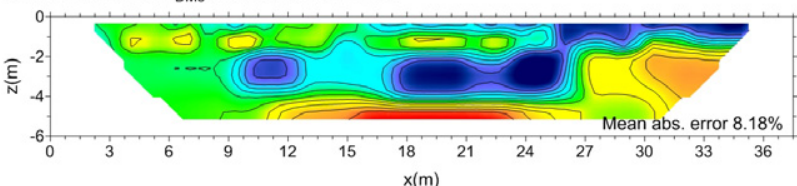

Figure 11. The same as in figures 9 and 10, for the line 7. In this case, the upper model (a) is the same as the one shown in figure 6(c). The anomaly B is still relatively well defined in all the models (b to e, respectively). Regarding T2, the loss of resolution is greater than in the previous case (see the text for a discussion of this result). 

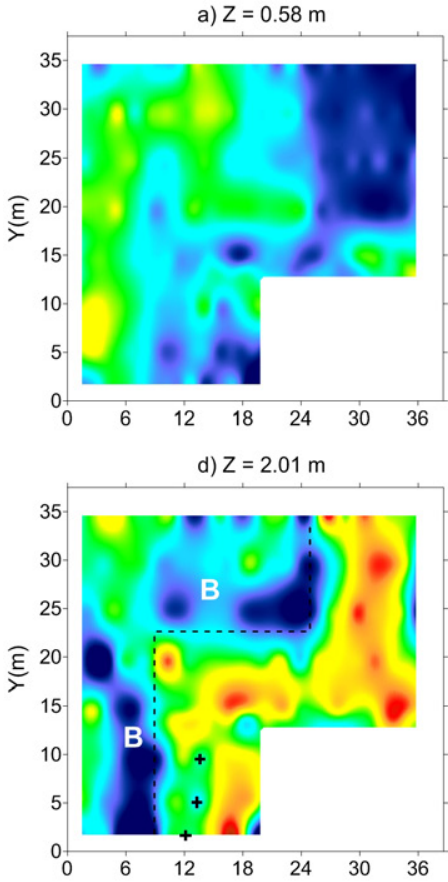

g) $Z=3.92 \mathrm{~m}$

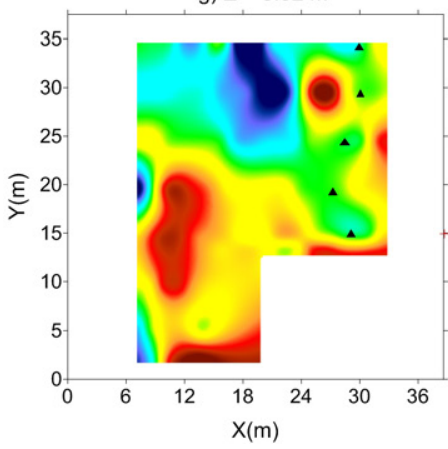

b) $Z=1.01 \mathrm{~m}$

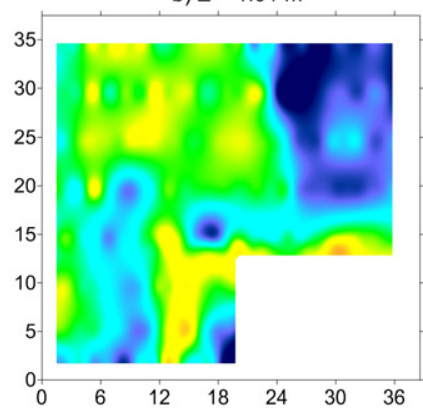

e) $Z=2.59 \mathrm{~m}$

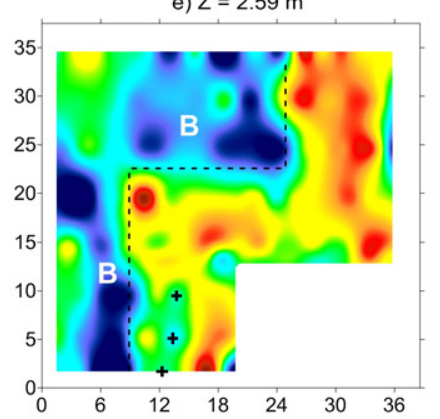

h) $Z=4.69 \mathrm{~m}$

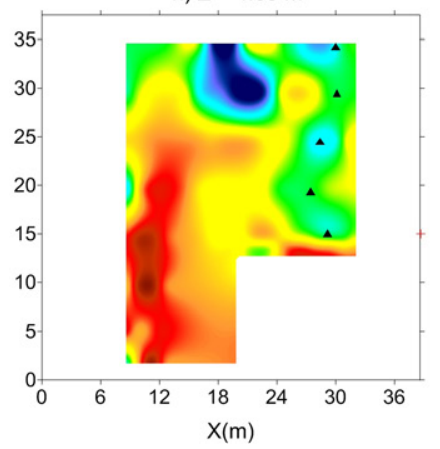

c) $Z=1.49 \mathrm{~m}$

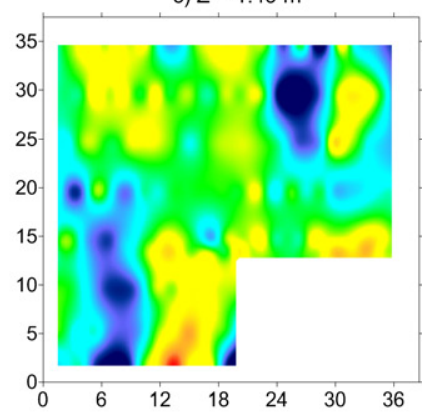

f) $Z=3.23 \mathrm{~m}$

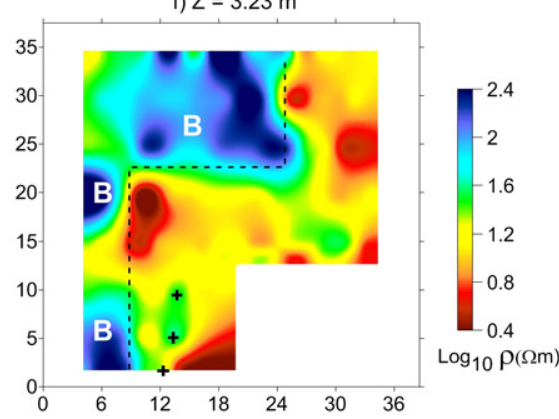

i) $Z=5.53 \mathrm{~m}$

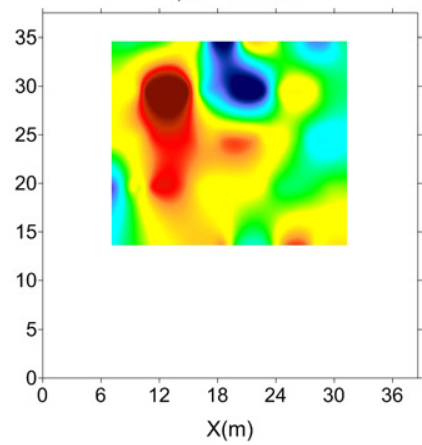

Figure 12. Constant-depth slices of the pseudo-3D image obtained by laterally interpolating the $2 \mathrm{D}$ models shown in figure 6 , at different depths (a to i, respectively). The localization of the anomalies T1 and T2 in those ERTs is superimposed for comparison, as crosses (in $\mathrm{d}$ to f) and triangles (in $g$ to h), respectively. The limits of the old basement (anomaly B) are indicated by a dashed line (d to f). The anomaly T2, associated to the N-S tunnel reported in historical records (figures 1(a) and 3), extends from North to South along the whole studied area; first it has a NNW-SSE direction, and for $y<20 \mathrm{~m}$, a NNE-SSW orientation. The anomaly T1, associated to a tunnel non-previously reported, has a NNE-SSW direction.

In figures $12(\mathrm{~d})$ and (e), a resistive zone can be observed between $x=17 \mathrm{~m}$ and $x=31 \mathrm{~m}$, for $y=13-14 \mathrm{~m}$, approximately. This zone is associated to the resistive anomaly appearing along the same $x$ values, for $1 \mathrm{~m}<z<3 \mathrm{~m}$, approximately, in the ERT corresponding to line 4, shown in figure 6(f). Due to the presence of the temporary construction previously mentioned, we could not perform transversal profiles (in the $y$ direction) to further investigate the characteristics of this anomaly; in particular, if it could eventually correspond to a continuity of $\mathrm{T} 1$ to the west, up to the location of $\mathrm{T} 2$.

To further clarify the final interpretation, in figures 13(a) and (b) we show the main electrical resistivity anomalies, superposed to the supposed localizations of the old basement and the known N-S tunnel, according to the historical information. The agreement between the results is rather good. In particular, performing the description from north to south: the localization and direction (NNW-SSE) of the northernmost part of the anomaly $\mathrm{T} 2$ are almost coincident with the ones reported of the N-S tunnel (figure 13(b)), and after that, there is also a change in direction of T2 from NNW-SSE to NNE-SSW, though this change occurs at a value of $y, 2$ or 3 meters greater than expected. It has to be taken into account that the available maps are not very precise, since they were drawn from approximated data, obtained at different periods of construction; hence, differences may appear in the positioning and trace of this tunnel. The probable continuity of this tunnel towards the south beyond what was reported in the historical maps is a relevant finding of this study. Regarding the anomaly T1, which has a NNE-SSW alignment (figure 13(a)), its shape in the ERTs shown in figure 6 resembled the shapes of the anomaly $\mathrm{T} 2$ that was associated to the N-S tunnel. On this basis, we concluded that $\mathrm{T} 1$ could indicate a stretch of a tunnel not previously reported, which should be connected with the E-W tunnel. As previously explained, its continuity to the west up to the location of $\mathrm{T} 2$ remains an open question. 
a) $z=2.59 m$

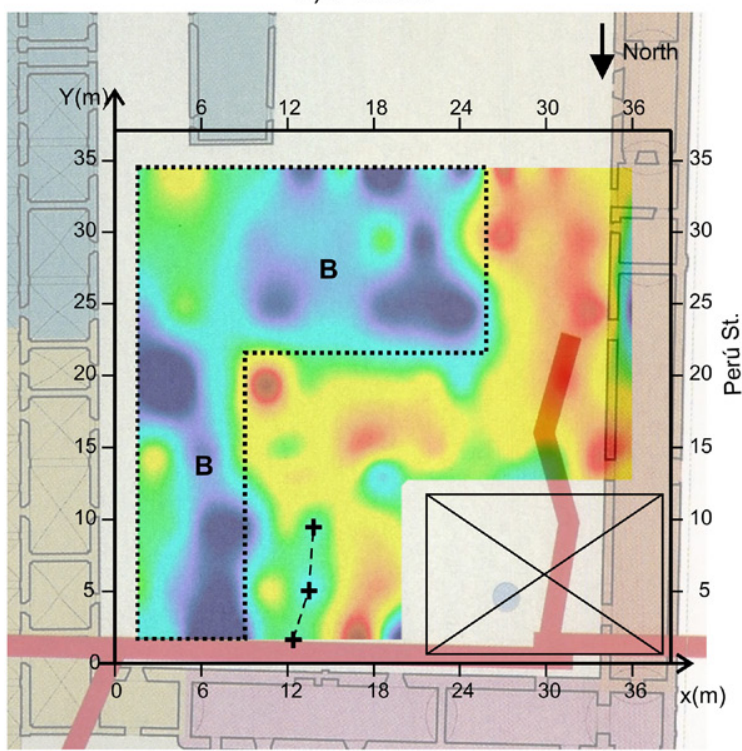

b) $z=4.69 m$

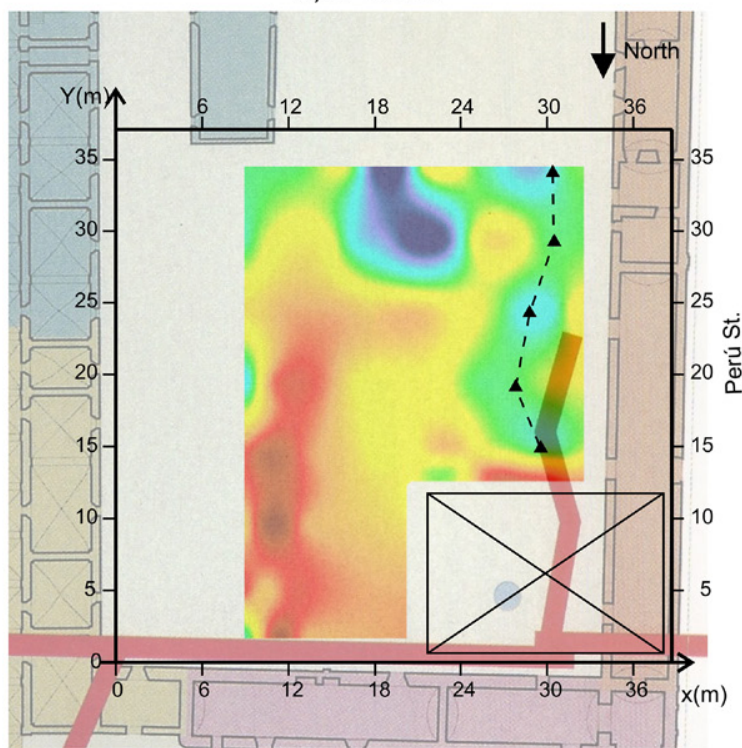

Figure 13. Summary of the main anomalies found at the studied area, together with the supposed location of the known N-S tunnel (red lines in (a) and (b)) and the remains of the old basement (dotted line in (a)), according to the historical information, for comparison. In figure 9, the anomaly that could correspond to a tunnel non-previously reported is indicated by crosses connected by a dashed line, while in (b), the obtained trace of the anomaly corresponding to the known tunnel is marked by triangles connected by a dashed line.

\section{Conclusions}

This work is an example of the application of geophysical methods at urban historical sites. The main goal was to detect tunnels built during the presence of Jesuits in the city of Buenos Aires, Argentina, between the 17th and18th centuries. An additional goal was to localize the remains of the basement of the former building of the Faculty of Sciences of the University of Buenos Aires, built in the 19th century. In particular, the detection of the tunnels was the most challenging. They were expected to have a width of about $1 \mathrm{~m}$, a height of $1.5-2 \mathrm{~m}$, and could be located at depths ranging from $2 \mathrm{~m}$ to more than $4 \mathrm{~m}$.

The main results can be summarized as follow:

Good lateral and vertical resolutions, as well as the required penetration depth were obtained carrying out dipole-dipole profiles, combining two different electrode spacings (1.5 and $3 \mathrm{~m}$, respectively). The high stacking used for the measurements reduced the random data errors arising from the environmental electric and electromagnetic noise, to a minimum. In addition, inverting the data acquired along each profile using a robust procedure reduced the effect of outlier data points (where the error comes from non-random sources) in the resulting models. In this manner, different anomalies were detected that could correspond to the described targets.

Those inversions were performed without providing any information to the program about data errors, which is the usual approach since often appropriate error estimations are not available. Occasionally, reciprocal measurements are done to estimate the errors, but this methodology is difficult to apply in urban environments, mainly due to time limitations in the accessibility to the study sites.

As a means of determining the reliability of the anomalies that were associated to the targets, we investigated the effect of data errors on the inversion results. For this purpose, we implemented a fast numerical procedure that allows us to obtain error estimations from the lateral variability of data. Using this procedure, we obtained different error estimations; and then, we analyzed the changes produced in the models when these errors were considered for the inversions. Thereby, we could disregard (or at least strongly diminish) the possibility that these anomalies were mere inversion artifacts.

Finally, the generation of a pseudo-3D model by transversally interpolating the $2 \mathrm{D}$ inversion results was very useful for the final interpretation. Since the separation of the profiles prevented the performance of a 3D inversion, plotting constant-depth slices of the interpolated 3D model allowing a much more clear alignment of the anomalies.

In summary, notwithstanding the difficult conditions, the applied methodologies allowed for the delimitation of remains of the old basement, delineatation of the trace of a tunnel reported in historical records and the establishment of its continuation beyond what was previously known, and the detectiion of another anomaly possibly associated to the presence of a tunnel not previously reported.

\section{Acknowledgments}

This work was partially supported by CONICET and ANPCyT-Argentina.

\section{References}

Banks I 2012 Geophysics and the great escape Leading Edge 31 916-20

Batayneh A T 2011 Archaeogeophysics-archaeological prospection-a mini review J. King Saud Univ. Sci. 23 83-9 
Beetham P and Hutchison R 2009 A geophysical investigation of a deep tunnel rock bore in Nottingham, UK Proc. of the Symp. on the Application of Geophysics to Engineering and Environmental Problems SAGEEP 2 pp 741-9

Bongiovanni M V and de la Vega M 2006 Geophysical studies under a cement yard in an archaeological site in N-E Argentina 18th EM Induction Workshop (El Vendrell, Spain, 2006) pp S6-12

Bonomo N, Osella A, Martinelli P, de la Vega M, Cocco G, Letieri F and Frittegotto G 2012 Location and characterization of the Sancti Spiritus Fort from geophysical investigations J. Appl. Geophys. 83 57-64

Dabas M, Camerlynck C, Freixas I and Camps P 2000 Simultaneous use of electrostatic quadrupole and GPR in urban context: investigations of the basement of the Cathedral of Girona (Catalunya, Spain) Geophysics 65 526-32

Dahlin T and Zhou B 2004 A numerical comparison of 2D resistivity imaging with ten electrode arrays Geophys. Prospect. 52 379-98

De Franceschini M and Marras A M 2010 New discoveries with geophysics in the Accademia of Hadrian's Villa near Tivoli (Rome) Adv. Geosci. 24 3-13

Drahor M G 2011 A review of integrated geophysical investigations from archaeological and cultural sites under encroaching urbanization in İzmir, Turkey Phys. Chem. Earth 36 1294-309

Drahor M G, Berge M A and Öztürk C 2011 Integrated geophysical surveys for the subsurface mapping of buried structures under and surrounding of the Agios Voukolos Church in İzmir, Turkey J. Archaeol. Sci. 38 2231-42

Edwards L S 1977 A modified pseudosection for resistivity and induced-polarization Geophysics 42 1020-36

Eppelbaum L V 2011 Study of magnetic anomalies over archaeological targets in urban environments Phys. Chem. Earth 36 1318-30

Furlong G 1994 Los Jesuitas y la Cultura Rioplatense (The Jesuits and the River Plate Culture) chapter 14: Arquitectos, escultores y pintores (Architects, sculptors and painters); chapter 19: Colegios, escuelas y bibliotecas (Colleges, schools and libraries) (Buenos Aires: Biblos) p 208

Leucci G and Negri S 2006 Use of ground penetrating radar to map subsurface archaeological features in an urban area J. Archaeol. Sci. 33 502-12

Levinton N 2012 Arquitectura de la Compañia de Jesus en Buenos Aires: la creación y el paso inclemente del tiempo (Architecture of the Company of Jesus in Buenos Aires: the creation and the inclement passing of time)1st edn (Buenos Aires: Contratiempo) ch 3, p 280

Loke M H and Barker R D 1996 Rapid least-squares inversion of apparent resistivity pseudosections by quasi-Nextonmethod Geophys. Prospect. 44 131-52

Loke M H, Acworth I and Dahlin T 2003 A comparison of smooth and blocky inversion methods in 2D electrical imaging surveys Explor. Geophys. 34 182-7

Loke M H, Chambers J E, Rucker D F, Kuras O and Wilkinson P B 2013 Recent developments in the direct-current geoelectrical imaging method J. Appl. Geophys. 95 135-56

Martinez-Lorenzo J A, Rappaport C M andQuivira F 2011 Physical limitations on detecting tunnels using underground-focusing spotlight synthetic aperture radar IEEE Trans. Geosci. Remote Sens. $4965-70$
Martino L, Bonomo N, Lascano E, Osella A and Ratto N 2005 Electrical and GPR joint prospecting at the Palo Blanco archaelogical site, NW Argentina. A case history Geophysics 71 193-9

Martorana R, Fiandaca G, Casas Ponsati A and Cosentino P L 2009 Comparative tests on different multi-electrode arrays using models in near-surface geophysics J. Geophys. Eng. 6 1-20

Mayochi E, Poitevin N and Gazaneo J 2008 Túneles de Buenos Aires, los túneles de la Manzana de las Luces (Tunnels of Buenos Aires, the tunnels of Manzana de las Luces) 3rd edn (Buenos Aires: Instituto de Investigaciones Históricas) p 34

Negri S and Leucci G 2006 Geophysical investigation of the temple of Apollo (Hierapolis, Turkey) J. Archaeol. Sci. 33 1505-13

Orfanos C and Apostolopoulos G 2011 2D-3D resistivity and microgravity measurements for the detection of an ancient tunnel in the Lavrion area, Greece. Near Surf. Geophys. 9 449-57

Osella A, Bongiovanni V and de la Vega M 2012 Development of a geoelectric device of capacitive contact for studying targets in very resistive zones Proc. Near Surface Geoscience 201218th European Meeting of Environmental and Engineering Geophysics p 48

Osella A, de la Vega M and Lascano E 2005 3D electrical imaging of an archaeological site using electric and electromagnetic methods Geophysics 70 101-7

Papadopoulos N, Sarris A, Yi M-J and Kim J-H 2009 Urban archaeological investigations using surface 3D ground penetrating radar and electrical Resistivity tomography methods Explor. Geophys. 40 56-68

Parasnis D S 1988 Reciprocity theorems in geoelectric and geoelectromagnetic work Geoexploration 25 177-98

Park S K and Van G P 1991 Inversion of pole-pole data for 3D resistivity structure beneath arrays of electrodes Geophysics 56 951-60

Szalai S, Novák A and Szarka L 2011 Which geoelectric array sees the deepest in a noisy environment? Depth of detectability values of multielectrode systems for various 2D models Phys. Chem. Earth 36 1398-404

Tawfik M, Farag K S and Ibraheem I M 2011 The efficiency of (VLF-EM) method in detecting buried old tunnels in the Egyptian Nile delta Society of Petroleum Engineers 73rd European Associations of Geoscientists and Engineers Conf. and Exhibition pp 5434-6

Tsokas G N, Tsourlos P I, Vargemezis G and Novack M 2008 Non-destructive electrical resistivity tomography for indoor investigation: the case of Kapnikarea church in Athens Archaeol. Prospect. 15 47-61

Tsokas G N, Tsourlos P I, Vargemezis G N and Pazaras N T 2011 Using surface and cross-hole resistivity tomography in an urban environment: an example of imaging the foundations of the ancient wall in Thessaloniki, North Greece Phys. Chem. Earth 36 1310-7

Weissel M 2010 InformeArqueológico No 4-Marzo. Plan integral de intervenciones Manzana de las Luces 2010-2016. Unidad de Gestión y Proyecto Plan Integral de Obras Manzana de las Luces. Comisión Nacional de Museos, de Monumentos y Lugares Históricos (personal communication)

Zhou B and Dahlin T 2003 Properties and effects of measurement errors on 2D resistivity imaging surveying Near Surf. Geophys. $1105-17$ 